Ebisu Ebisu

Études japonaises Études japonaises

$57 \mid 2020$

Les architectes de l'ère Heisei (1989-2019). Rôles, statuts, pratiques et productions

\title{
CARRÉ Guillaume, Avant la tempête. La Corée face à la menace japonaise (1530-1590)
}

Paris, Institut d'études coréennes du Collègue de France, collection « Kalp'i - Études coréennes », 2019, 406 p.

\section{Yannick Bardy}

\section{(2) OpenEdition}

\section{Journals}

Édition électronique

URL : http://journals.openedition.org/ebisu/5511

DOI : $10.4000 /$ ebisu. 5511

ISSN : 2189-1893

Éditeur

Institut français de recherche sur le Japon à la Maison franco-japonaise (UMIFRE 19 MEAE-CNRS)

Édition imprimée

Date de publication : 15 décembre 2020

Pagination : 476-477

ISSN : $1340-3656$

Référence électronique

Yannick Bardy, " CARRÉ Guillaume, Avant la tempête. La Corée face à la menace japonaise (1530-1590) 》, Ebisu [En ligne], 57 | 2020, mis en ligne le 20 décembre 2020, consulté le 29 mars 2021. URL : http:// journals.openedition.org/ebisu/5511; DOI : https://doi.org/10.4000/ebisu.5511 


\section{Recension}

\section{Carré Guillaume,} Avant la tempête. La Corée face à la menace japonaise (1530-1590), Paris, Institut d'études coréennes du Collègue de France, collection "Kalp'i - Études coréennes », 2019, 406 p.

Avant la tempête. La Corée face à la menace japonaise (1530-1590) est un ouvrage sur les relations entre la Corée et le Japon au $\mathrm{XVI}^{\mathrm{e}}$ siècle. Bien que d'une grande érudition, il s'adresse à un lectorat large et invite à la lecture tous ceux qui travaillent sur les pays bordant la mer de Chine orientale. Mobilisant les rares sources disponibles tant au Japon qu'en Corée, Guillaume Carré propose un regard qui dépasse le seul intérêt pour la piraterie dans cette région ou celui de l'histoire nationale, qu'elle fut coréenne ou japonaise.

Ce livre en six chapitres peut être divisé en trois parties, dont l'une expose le contexte et les enjeux, l'autre les questions de stratégie et d'armement pour les mettre en œuvre, et la dernière traite des wakō 倭寇, ces pirates, contrebandiers et commerçants qui n'étaient pas tous japonais, du moins à cette époque.

La première partie s'ouvre sur la question de l'argent japonais: au $\mathrm{XVI}^{\mathrm{e}}$ siècle, ce métal très demandé tant en Chine qu'en Europe, en manque de numéraire, est produit au Japon en des quantités estimées à un tiers de la production mondiale de l'époque. Or, pour la cour de Chŏson 朝鮮, qui avait obtenu de la Chine qu'elle renonçât à la part en argent du tribut annuel, l'arrivée de ce métal par cargaisons entières est un casse-tête diplomatique. Dans ces pages, l'auteur traite de la réaction de la cour à ces arrivées, et des raisons qui ont pu mener à la limitation des importations ou au contraire à l'acceptation de certaines cargaisons. Il y est également question des conséquences économiques et politiques de ces introductions massives d'argent en Corée. L'auteur discute ensuite du système de défense et de ses carences, telles qu'elles apparaissent lors du raid de Tallyang 達梁 (1555) par des wakō. Il présente le système des camps militaires, chin'gwanje 鎮管制 et montre un système de conscription fragilisé par la corruption et la désertion.

Guillaume Carré poursuit par l'étude de la "stratégie victorieuse ", chesŭng pangnyak 制勝方略, dont l'historiographie commune, fondée sur les mémoires de l'ancien ministre 
Yu Sŏng-Nyong 柳成龍, considère qu'elle aurait été mise en place après Tallyang et aurait causé l'effondrement de la défense coréenne face aux armées de Hideyoshi 秀吉. Lauteur émet des doutes sur le témoignage de Yu Sŏng-Nyong, ainsi que sur l'origine et le nom de cette stratégie. Au final, cette réforme paraît peu profonde. S'ensuit une étude de la pensée de Yu Sŏng-Nyong en matière militaire, et de ses motivations, puis une discussion sur la stratégie défensive dans le Nord du pays et son adaptation aux réalités du Sud. Le chapitre suivant porte sur le développement et la modernisation des armes à feux en usage dans l'armée coréenne, ainsi que sur l'échec de la cour à dépasser l'expérimentation pour équiper ses soldats d'armes à la hauteur des arquebuses japonaises.

Enfin, l'auteur fait le point sur l'identité des wakō et sur l'alliance entre la cour de Chŏson et le domaine de Tsushima 対馬. Concernant les wakō, Guillaume Carré commence par traiter des développements historiographiques récents, notamment ceux de Tanaka Takeo et Murai Shōsuke, qui ont contribué à l'établissement d'une vision multiethnique et transrégionale de ces groupes de pirates, ainsi que d'autres travaux comme ceux de Yi Yŏng qui combattent ces thèses. Ensuite, il rappelle le contexte de l'interdiction maritime imposée par la Chine, qui ne pouvait que donner naissance à toute une faune de hors-la-loi. Le point sur Tsushima s'étend sur le rôle du clan Sō 宗, qui contrôle Tsushima et les populations maritimes qui y vivent, et que la Corée estime responsable du contrôle des wakō, en échange de droits commerciaux. Cette politique allait être mise à mal par la concurrence accrue des populations de l'archipel de Gotō (Gotō rettō 五島列 島), avant de s'achever par la prise en main des affaires internationales par Hideyoshi, qui devait mettre fin du même coup à la piraterie.

À travers cette étude sur les échanges diplomatiques, techniques et économiques, mais également sur la réalité de la menace wakō, Guillaume Carré, par son travail critique, soutenu par sa capacité à croiser les sources des pays concernés, réussit le tour de force de montrer la politique de la Corée envers ses deux voisins. D'une grande clarté, l'auteur aurait cependant pu s'épargner certaines répétitions au fil des chapitres.

Yannick BARDY Maître de conférences à l'université de Lille 